\title{
A methodological note about the analysis of the economic growth and environment
}

\begin{abstract}
The models of Economic Growth in the traditional literature describe associated dynamics to closed systems in most of their presentations. With the incorporation of the Environment and its functions to these models, simple and closed linear systems become complex systems with multiple feedback mechanisms and non-linearities. In this context, the goal of Sustained Growth is uncertain, and the possibility of sustainability is conditioned to deep structural changes in the productive system.
\end{abstract}

Keywords: growth, environment, sustainability, complex systems, feedback
Volume 2 Issue 8 - 2017

\section{Silvia London}

Department of Economics, Institute of Economic and Social Research of the South, Argentina

Correspondence: Silvia London, IIESS, CONICET-UNS, Dept. of Economics UNS, San Andres 800, Bahia Blanca, Argentina, Tel 542-9|4-595-138, Fax 542-9|4-595-139,

Email slondon@uns.edu.ar

Received: October 29, 2017 | Published: December 13, 2017

\section{Introduction}

The Theory of Economic Growth has its formal beginning from the seminal developments of Harrod \& Domar. ${ }^{1}$ Subsequently, in view of the well-known criticisms of these developments, particularly the intrinsic instability and the impossibility of achieving a stable equilibrium in the Harrod model, the Solow growth model emerges. In its full version, the dynamics in the Solow model take place in a balanced growth path in which consumption and output per capita grow at the rate of technical progress (exogenous). The 1980s saw the emergence of important literature, both theoretical and empirical, with sophisticated mathematical models based on Solow's ideas. It is from the ' 90 s that the interest in the environment (already present in the formulations of the classics on economic growth) is incorporated into formal neoclassical analysis, based on the concept of Sustainable Growth. In this context, Solow ${ }^{2}$ affirmed that the conservation of the stock of physical and natural capital is sufficient condition for sustainability, and that investment in environmental improvement is the necessary condition for the deteriorated stock to maintain a level at least constant. The proposed concept of sustainability establishes that the level of life in intergenerational terms should remain at least constant. ${ }^{3}$ In this formal context, the consideration of intertemporal decisions involves on the one hand the incorporation of natural capital to the model (as a factor of production) and its degree of complementarily between physical capital (human and not) and natural capital. On the other hand, there is a degree of uncertainty in the results obtained, due to the limits to knowledge about future environmental behavior. The purpose of this paper is to present the methodological foundations for a formal framework of economic growth analysis incorporating environmental restrictions.

\section{The incorporation of the environment to the analysis of economic growth}

The environment is the origin of all the resources used by man. It is a system formed by interrelated natural and artificial elements that can be modified by human action. It is about the context that conditions the life of society and that includes natural, social and cultural values that exist in a specific place and time. The inclusion of the environment in the economic analysis allows us to move from a closed system of production (Figures $1 \& 2$ ). From the formal point of view, the transition to a system like the one described in (b) cannot be fully captured with the only incorporation of natural capital to the model, as proposed by Solow. ${ }^{2}$

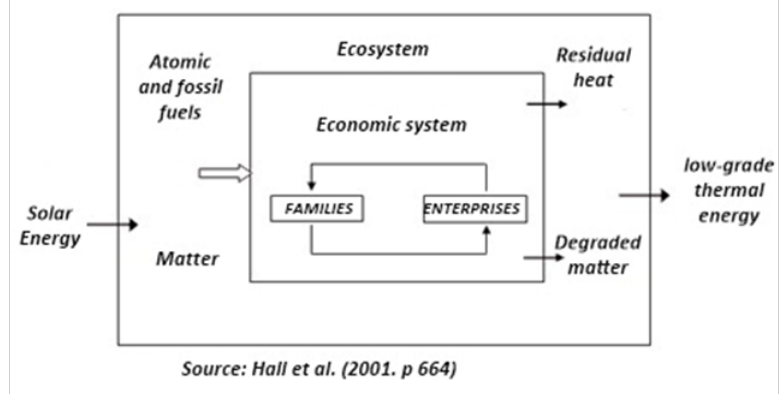

Figure I Circular flow of income.

There are several elements to be considered:

1. Solow's model with natural capital $(\mathrm{KN})$ considers that there is absolute substitution between KN and physical, human and nonKF capital. In this sense, the limits to growth are still far away, and such limits move away as they occur:

a. Improvements in technological change,

b. Improvements in recycling,

c. Prices assignment to environmental goods, and

d. The decrease in the population rate, among others.

2. This intertemporal analysis has a precise antecedent: Hicks speaks of maximum amount that can be spent without reducing actual consumption in the future, while Hartwick, Solow ${ }^{1,2}$ also define intertemporal well-being: the deterioration of natural capital must be compensated with physical capital. Based on the Hotelling rule (capital and natural resources are perfect substitutes), the objective of sustained growth seems to be consistent over time, even with the consideration of $\mathrm{KN}$ and the environment in the analysis. ${ }^{3}$ However, this view of environmental economics raises strong objections (particularly from the ecological economy), based on the existence of irreplaceable ecological and environmental goods. Figure 2 shows how, in a system whose only external source of energy is solar, the laws of thermodynamics (first and 
second law) modify the productive and vital capacity (in general) of the system) ${ }^{4,5}$ How is the steady state value reinterpreted in the Solow model when incorporating human capital (KN)? Leaving aside the criticisms of this concept (in particular the concept of convergence that derives from the existence of a steady state) the problem is reduced to comparing the steady state (welfare level) in the analysis with and without KN. The formal difficulties associated with this approach consider the aforementioned (degree of substitution between physical and natural capital) and the need to incorporate the $\mathrm{KN}$ depreciation curve. On the other hand, the Hotelling rule should be included whereby non-renewable natural resources are not extinguished and the production of goods is positive to avoid a long-term stationary state ${ }^{3}$

3. Intertemporal analysis requires a valuation (prices assignment) to environmental assets. This aspect raises many difficulties that will not be considered in this work. However, this assessment is crucial when it comes to understanding intertemporal assignments.

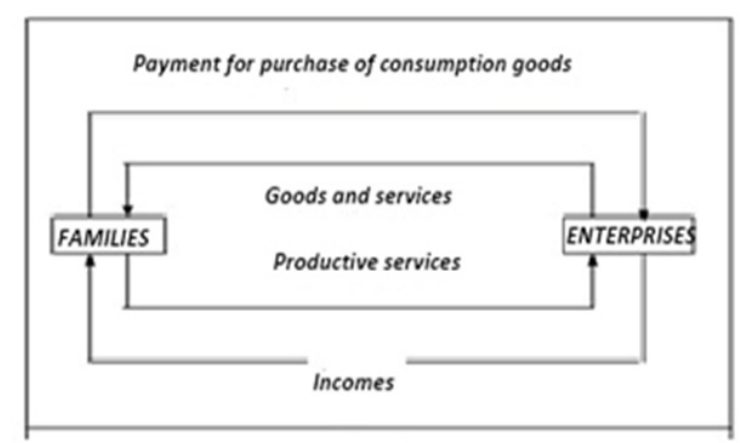

Source: Adapted from Hall et all (2001, p. 664)

\section{Figure 2 Complex system.}

\section{Growth and environment: formal framework}

Based on the above considerations, the way to find a formal model that represents the incorporation of the environment in all dimensions does not seem to be a trivial process. If we incorporate the objective of "sustained growth" (as described and analyzed in economic growth models), this difficulty increases. From the formal point of view, the function to be maximized is that of the utility of the representative individual or society, subject to the restrictions imposed by the model. The incorporation of the $\mathrm{KN}$ involves its valorization: if the objective is to maximize the sum of the consumption discounted in time, subject to the restriction of natural resources, the solution is known: the price increases in the same proportion as the discount rate, the level of consumption tends to zero and is equal to the discount rate multiplied by the elasticity of marginal utility of consumption that has to have a negative value. ${ }^{6}$ However, individuals do not consider the environment as an input of the welfare function but derive their utility directly from its use. "This would lead to denying the affirmation that the permanence in the level of consumption implies maintaining the level of well-being", thus it is suggested to include in the utility function the stock of resources (op.cit.). Heal ${ }^{6}$ shows that the solution is characterized by a value $\mathrm{KN} *$ in which the marginal rate of substitution between $(\mathrm{KN})$ and consumption (equal to zero) is equal to the discount rate $\delta$. "In both cases it is clear that the road to sustainability will be one where consumption is zero: in the first case the stock remains constant (KN0), in the gold rule, in the second case the stock (KN*) Is much smaller." Sotelsek \& Ahamdanech ${ }^{3}$ link growth with the environment and establish, from a qualitative analysis (graphically) that solutions can be assumed with problems of growth and environmental degradation, growth and environmental degradation and an environmentalist strategy. In the case of economic growth with environmental considerations, the discrete approach is presented as more intuitive and descriptive. From the point of view of the theoretical tradition, Diamond's growth model of overlapping generations would seem to be a good starting point (Romer 2001). London ${ }^{7,8}$ proposes a formal analysis where they are incorporated under this approach, moving from previous models that describe simple systems to a complex one. The description of Figure (b) can be interpreted under the functions of the Environment. Pearce ${ }^{9}$ points out four functions that give value to the environment and that synthesize their interrelations with the economy, allowing to focus the discussion around the management of natural resources and environmental assessment.

\section{These functions are:}

a. Production function,

b. Waste and waste receiver,

c. Proportion of natural goods and

d. Constitution of "an integrated system that provides the means to sustain all kinds of life".

By concentrating the present discussion on the first three functions4, the dynamic approach incorporates into the production function the renewable and non-renewable natural resources, and the relations between production and consumption, and pollution, degradation and natural recycling capacity. If the rate of use of nonrenewable natural resources were constant, at the limit, production would become zero and humanity would collapse (in the very long term), as long as the non-renewable resources of the production function cannot be dispensed with. For the case in which it was variable in time, let us suppose that it is dependent on investment: it will be less to greater use of renewable energies and replacements of inputs from fossil resources (for example, fertilizers) by renewable natural resources (for example, organic fertilizers). This functional relationship is specified in terms of flows, so its interpretation should incorporate additional considerations. Particularly in relation to the role of nonrenewable resources in the production function: in the very long term it is possible to think that substitution of factors can occur in perfect form between renewable and non-renewable resources (or return to the catastrophe scenario). To do this, a threshold value (minimum) should be incorporated for the non-renewable ones, below which the participation of non-renewable resources in the production function becomes minimal. Lets bear in mind that the production function of the final good does not consider the 4th function of the environment, that is, to be the sustenance of life, so that non-renewable natural resources are considered here as an INPUT of production.

On the other hand, for this substitution between renewable and non-renewable resources to exist, there must be a specific degree of technological development that allows it (renewable energies and storage capacity, for example), changes in consumption and production habits (in particular, widespread presence of plastic materials manufactured with hydrocarbons), etc. The examples are extensive and include hydrocarbons, minerals and in the limit, water. Although the exhaustion frontier seems far away, the substitution of renewable non-renewable natural resources seems crucial, and in this scenario time plays a leading role. The values adopted by the recovery rate (natural recycling capacity) will depend positively on the investment (I) made in the sector (example: clean technologies, land 
reclamation, etc.) and negatively on pollution levels (produced by $\mathrm{C}$, consumption, Y, production, I) in the previous period, which reduce the capacity of the environment to absorb waste, which impacts on the quality and endowment of natural resources. Again we consider that Investment in green technologies depends on technical progress. The problem to be solved remains analogous to Diamond's model: individuals will want to maximize their consumption, subject to their budget constraint.

\section{Towards a systemic analysis}

London $^{7}$ presents the equations that summarize the foregoing relationships. Synthetically, the system is described as:

$$
Y_{t}=f\left(Y_{t-1}, Y_{t-2}, \text { dist }_{t-1}\right)
$$

Where $\operatorname{dist}_{\mathrm{t}-1}$ describes the technological distance between sustainability requirements and current tencology. This equation is non-linear, non-homogeneous and its analytical resolution is not possible. ${ }^{10}$ However, in general terms and without specifying the functional relationships, it is possible to perform a set of simulations (scenario analysis). Under the neoclassical assumption of intertemporal maximization of consumption, under the assumption of sustainable management of natural resources and in a standard constellation of savings-investment in capital goods, the system collapses due to the inability of the environment to absorb the waste and the resulting pollution of productive activities and consumption. This result is extended over time if consumption levels are reduced and resources are allocated to mitigative and "green" investments. The best results are achieved when consumption is reduced further, resources are allocated to green technologies and natural resources are used below the sustainable level. Given the complex configuration of the system (of the spin glasses style), for certain parametric configurations, oscillatory or chaotic behaviors of the product are found. Although reality does not show such behavior in the periodicity of the analysis, the qualitative characteristics of this type of models suggest an intrinsic instability in it that needs to be corrected. In the simulations carried out, the exogenous technical progress is considered. However, the role played as a determinant of behavior deserves particular attention. One way is the indigenization of technical progress and technology (considering technical progress as an advance towards more and better green technologies). For this, the framework of patent models of Aghion \& Howitt ${ }^{11}$ is shown as adequate. Finally, in the future line of analysis, other variables that modify the aggregate growth and consumption results will be incorporated: the possibility of recycling, the "temporary postponement" of polluting activities (cumulative contamination), and the effects of technical progress on consumption, and fundamentally, to incorporate the dynamics of environmental quality, as another subsystem in interaction with the economic one. ${ }^{12-16}$

\section{Acknowledgements}

The author gratefully acknowledges the participants of the seminars that took place in Uruguay in October 2016 and OctoberNovember 2017 (UDELAR, Montevideo, and UDELAR-CURE, La Paloma).

\section{Conflicts of interest}

The author declares that there is any financial interest or any conflict of interest exists.

\section{Funding}

None.

\section{References}

1. Jones Hywel G. Introduction to modern theories of economic growth, Antoni Bosch Ed. Argentina; 1979

2. Solow RM. Siena Lectures on Endogenous Growth Theory, Siena sept, Italy; 1992.

3. Sotelsek Daniel, Ahamdanech Ismael. Reflections on growth, the environment and poverty. Industrial economy. 2008; 367 p.

4. Ballestero Marjorie Hartley. Environmental economics and ecological economics:A critical balance of their relationship, Economy and Society, 2008. p. 55-65.

5. Castro Bonaño JM. Indicadores de Desarrollo Sostenible Urbano. Una Aplicación para Andalucía, Edición electrónica gratuita. 2009.

6. Arrow Kenneth, Bolin Bert, Costanza Robert, et al. Economic Growth, Carrying Capacity, and the Environment. Science. 1995;52(2):91-95.

7. London Silvia. Economic analysis under a systemic approach:realism versus prediction? multidisciplinary workshop in complex systems Cultural Center of La Paloma - Rocha, Uruguay, USA; 2017.

8. London Silvia. Environment and Economic Growth:complex dynamics and uncertainty, workshop economic dynamics:theory and applications, (GIDE) University of the Republic (UDELAR), USA; 2016.

9. Pearce DW. The Limits of Cost Benefit Analysis as a Guide to Environmental Policy, Kyklos. 1976;29(1):97-112.

10. London Silvia. Economic growth, human capital and negative externalities:stability and chaos. Brazilian Journal of Business Economics, Catholic University of Brasilia. 2009;9(1):7-15.

11. Aghion P, Howitt P. The economics of growth. The MIT Press Cambridge, Massachusetts London, England; 2009.

12. Brida Juan Gabriel, London Silvia, Rojas Mara. Tourism as a source of economic growth:impact of agents' intertemporal preferences. Economic Research Magazine (Mexico) July-September, 2014;LXXIII:289.

13. Costanza Robert, Daly Herman E. Natural Capital and Sustainable Development Conservation Biology. 1992;6(1):37-46.

14. Cox Michael. Advancing the diagnostic analysis of environmental problems. International Journal of the Commons. 2011;5(2):346-363.

15. Epstein Graham. Missing ecology: integrating ecological perspectives with the social-ecological system framework. International Journal of the Commons. 2013;7(2):432-453.

16. Rodríguez Tapia, Lilia, Ruiz Sandoval Valverde, et al. The concept of natural capital in exogenous growth models. Economic Analysis, Autonomous Metropolitan University. Azcapotzalco Unit, Federal District, Autonomous Metropolitan University. Azcapotzalco Unit, Federal Districtvol, USA. 2001;XVI(33):109-128. 